BMJ Paediatrics Open

\section{Cord blood microRNA-376c and microRNA-1268a as biomarkers for neonatal hypoxic-ischaemic encephalopathy: a diagnostic accuracy study}

To cite: Midan DAR, Bahbah WA, Fayed DA, et al. Cord blood microRNA-376c and microRNA-1268a as biomarkers for neonatal hypoxicischaemic encephalopathy: a diagnostic accuracy study. BMJ Paediatrics Open 2021;5:e001258. doi:10.1136/ bmjpo-2021-001258

Received 19 August 2021 Accepted 26 November 2021

\section{Check for updates}

(c) Author(s) (or their employer(s)) 2021. Re-use permitted under CC BY-NC. No commercial re-use. See rights and permissions. Published by BMJ.

${ }^{1}$ Pediatric department, Faculty of medicine,Menoufia University, Shebin El Kom, Menoufia, Egypt ${ }^{2}$ Biochemistry department, Faculty of Science,Menoufia University, Shebin El Kom, Menoufia, Egypt ${ }^{3}$ Medical Biochemistry and Molecular biology department Faculty of Medicine,Menoufia University, Shebin El Kom, Menoufia, Egypt

Correspondence to Dr Dina Abdel Razek Midan; dina.abdelkader@med.menofia. edu.eg

\section{ABSTRACT}

Background Hypoxic-ischaemic encephalopathy (HIE) is one of the most common causes of morbidity and mortality among neonates. There is a critical need for noninvasive novel biomarkers to detect HIE early, predict its outcomes and monitor its progression. We conducted this observational study to assess the relative expression of miRNA-376c and miRNA-1268a in cord blood as potential diagnostic and prognostic biomarkers for HIE.

Methods A total of 100 neonates divided into two independent groups were included. The case group included 50 neonates with HIE, while the control group included 50 matched healthy neonates. Relative expressions of miRNA-376c and miRNA-1268a were measured in whole cord blood at birth using real-time PCR. Results Compared with the control group, patients with HIE had a significantly lower median level of miRNA$376 \mathrm{c}(0.168, \mathrm{IQR}=0.011-0.411$ vs $1, \mathrm{IQR}=0.80-1.20)$ and a higher median level of miRNA-1268a (13.46, $\mathrm{IQR}=2.7-22.8$ vs $1, \mathrm{IQR}=0.4-1.6)$. Comparing neonates with HIE who survived versus those who did not survive, no statistically significant difference between the groups in terms of miRNA-376 $\mathrm{c}$ and miRNA-1268a $(\mathrm{p}=0.124$ and $\mathrm{p}=0.279$ ) was elicited. Our diagnostic analysis showed that, at 0.90 points, miRNA-376c has a sensitivity and a specificity of $88 \%$ and $68.40 \%$, with an area under the curve of $84 \%$. At 2.70 points, miRNA-1268a has a sensitivity and a specificity of $76 \%$ and $100 \%$, with an area under the curve of $96 \%$.

Conclusion The relative expression of miRNA-376c and miRNA-1268a was altered in the cord blood of neonates with HIE. In addition, they have moderate diagnostic accuracy in detecting HIE.

\section{INTRODUCTION}

Hypoxic-ischaemic brain injury is a considerable common cause of neonatal encephalopathy. ${ }^{1}$ Hypoxic-ischaemic encephalopathy (HIE) is estimated to affect 1.5 out of every 1000 live births. ${ }^{2}$ Up to $60 \%$ of neonates will die by 2 years or will have critical disorders

\section{What is known about the subject?}

Hypoxic-ischaemic brain injury is a considerable common cause of neonatal encephalopathy.

- Hypoxic-ischaemic encephalopathy is estimated to affect 1.5 out of every 1000 live births, with a considerable mortality rate.

- miRNA-376c plays a vital role in the regulation of cell growth and proliferation, while miRNA-1268a is involved in embryogenesis and cell differentiation.

\section{What this study adds?}

The expression of miRNA-376c and miRNA-1268a was altered in the cord blood of neonates with HIE.

- Patients with HIE had a significantly lower level of miRNA-376c than healthy controls and a higher level of miRNA-1268a.

The expression of miRNA-1268a and miRNA-376c was comparable among HIE cases who survived and those who did not survive.

such as mental retardation or epilepsy. ${ }^{3}$ Finding diagnostic and prognostic biomarkers for HIE helps clinicians identify disease progression, predict the clinical outcomes and provide neuroprotective strategies. ${ }^{3}$

Previous studies have extensively identified new potential biomarkers for HIE in different types of samples, including cord blood, cerebrospinal fluid, serum and urine. ${ }^{45}$ These potential biomarkers include interleukin 6 , glial fibrillar acidic protein, myelin basic protein and ubiquitin carboxyl-terminal hydrolase L1 in cord blood. ${ }^{4}$ Interestingly, microRNA (miRNA) expression is altered in neonates with HIE and has been suggested as potential biomarkers for HIE in umbilical cord blood. ${ }^{56}$ 
miRNAs are small, non-coding RNA molecules with a high degree of conservation that post-transcriptionally regulate the expression of about $30 \%$ of human genes. ${ }^{7}$ miRNAs bind to its complementary sequence of 3-untranslated regions of the messenger RNA of the target gene and stimulate its degradation. Further, miRNAs play essential roles in regulating pathways in cell proliferation, migration, apoptosis and drug resistance. ${ }^{78}$ miRNA-376c belongs to an evolutionarily conserved miRNA family that includes genes located on human chromosome 14 in a syntenic cluster. ${ }^{9}$ miRNA-376c plays a vital role in the regulation of cell growth and proliferation and was found to have low expression in the umbilical cord whole blood of neonates with HIE. Further, its upregulation reduced cell injury induced by oxygen and glucose deprivation in cell lines. ${ }^{6}$ Furthermore, miRNA-1268a is a critical abundant miRNA functionally involved in embryogenesis and cell differentiation. ${ }^{10}$ High expression of miRNA-1268a is considered a risk factor for stroke. ${ }^{11}$ The RNA-induced silencing complex allows miRNAs to perform their regulatory functions. Production, replication, differentiation and apoptosis are some of the biological processes that miRNAs regulate. ${ }^{12}$ Furthermore, exosomal miRNAs are emitted into the fluids of the body and play a role in intercellular communication, suggesting that they may be used as diagnostic biomarkers. ${ }^{13}$ We conducted this study to evaluate the role of miRNA-376c and miRNA1268a in the diagnosis and prediction of neonatal HIE.

\section{METHODS}

We conducted this diagnostic accuracy study at the Neonatal Intensive Care Unit of Menoufia University Hospital, in cooperation with the Biochemistry Department, Faculty of Science, and the Medical Biochemistry and Molecular Biology Department, between January 2020 and January 2021. Written consent was obtained from the guardian of each participant included in the study.

\section{Patient and public involvement statement}

Patients and/or the public were involved in the design, conduct, reporting and dissemination plans of this research. Public healthcare clinics, but not families, were involved in the content and design.

\section{Eligibility criteria \\ Inclusion criteria}

For the case group, we targeted all term neonates exposed to perinatal asphyxia and only included neonates with clinical manifestations suggestive of neonatal HIE according to the clinical Sarnat staging system. ${ }^{14}$ The control group included a group of age-matched healthy neonates. Controls were full-term neonates with no history of perinatal risk factors for asphyxia and with normal Apgar scores at the first and fifth minute after birth, without the need for resuscitation. Weight was not used for matching as we aimed to study weight as one of the risk factors.

\section{Exclusion criteria}

We excluded the following:

- Neonates with congenital infections or congenital anomalies.

- Neonates with chromosomal abnormalities.

- Neonates with suspected inborn errors of metabolism.

- Preterm neonates (less than 37 weeks).

- Infants of mothers with diabetes.

- Neonates with sepsis.

All neonates were subjected to a detailed history taking, clinical examination as well as laboratory investigations. Routine investigations included complete blood count, quantitative $\mathrm{C}$ reactive protein (CRP), blood gases, electrolytes, liver function test, kidney function test, serum ammonia and lactate. Specific investigations assessed miRNA-376c and miRNA-1268a levels using the real-time PCR technique.

\section{Clinical Sarnat staging system}

First, all included cases were subjected to a detailed neurological examination for HIE performed within 24 hours of birth. Specifically, physical examination focused on assessing the consciousness level, muscle tone, both tendon and complex reflexes, and autonomic function, as described in the Neonatal Research Network study (NICHD). ${ }^{15}$ The results of the neurological examination were augmented with encephalographic findings suggesting the affection. We classified neonates with a diagnosis of HIE based on the Sarnat staging system. ${ }^{14}$ According to this staging, neonatal HIE can be categorised into mild cases (stage I), moderate cases (stage II) and severe cases (stage III).

\section{Radiological assessment}

Magnetic resonance imaging (MRI) was performed on the eighth day of admission. T1 and T2 images, as well as diffusion-weighted imaging, were used. We assessed the MRI studies for occurrence and magnitude of pathological shortening of $\mathrm{T} 1$ as well as prolongation of T2, cerebral haemorrhage, limited diffusion and periventricular leucomalacia. We further graded the MRI findings using the following criteria ${ }^{1617}$ :

- Grade 0: normal MRI findings.

- Grade 1a: MRI findings show minor cerebral impairment that does not affect the basal ganglia or the internal capsule's posterior limb.

- Grade 1b: MRI findings show more substantial cerebral involvement without involving the basal ganglia or the internal capsule's posterior limb.

- Grade 2a: MRI findings show abnormalities involving the basal ganglia or the internal capsule's posterior limb with no cerebral abnormalities.

- Grade 2b: MRI findings show abnormalities involving the basal ganglia and the internal capsule's posterior limb. 
- Grade 3: MRI findings show devastation on all sides of the hemisphere.

\section{Blood sample collection and real-time PCR}

Samples were obtained from the umbilical cord blood from all included neonates at birth. We placed $3 \mathrm{~mL}$ of cord blood samples from the included neonates into Tempus Blood RNA Tube and were biobanked at $-80^{\circ} \mathrm{C}$ until RNA extraction. miRNA extraction was performed using $100 \mu \mathrm{L}$ of fresh whole blood samples. Total RNA, including miRNA, was extracted using miRNeasy Isolation Kit (QIAGEN, USA). We assessed the concentration as well as the quality of RNA using a NanoDrop instrument (Thermo Scientific, USA) and stored the RNA extract at $-80^{\circ} \mathrm{C}$. In order to produce complementary DNA (cDNA), we performed reverse transcription using the miScript II RT Kit (QIAGEN, USA). Preparation of the constituents of the reverse transcription was performed on ice in a total volume of $20 \mu \mathrm{L}$. RT Master Mix was prepared with $4 \mu \mathrm{L}$ miScript HiSpec RT buffer, 2 $\mu \mathrm{L}$ of miScript Nucleics Mix, $2 \mu \mathrm{L}$ miScript Reverse Transcriptase and $1 \mu \mathrm{g}$ of miRNA template. The volume was then completed to $20 \mu \mathrm{L}$ by nuclease-free water.

Incubation was performed using the 2720 Thermal Cycler (Singapore Applied Biosystems) for one cycle: $37^{\circ} \mathrm{C}$ for 1 hour to activate the reverse transcriptase enzyme, followed by $95^{\circ} \mathrm{C}$ for $5 \mathrm{~min}$ for inactivation. The cDNA obtained was stored at $-20^{\circ} \mathrm{C}$ until real-time PCR. Real-time PCR was carried out using miScript SYBR Green PCR Kit (QIAGEN, USA). Prior to amplification, we diluted the cDNA samples obtained using nucleasefree water, with a $1: 5$ ratio $(16 \mu \mathrm{L}$ of nuclease-free water and $4 \mu \mathrm{L}$ cDNA). We applied a cumulative volume of $25 \mu \mathrm{L}$, which included SYBR Green Master Mix (12.5 $\mu \mathrm{L})$, nuclease-free water $(3.5 \mu \mathrm{L})$, diluted cDNA $(4 \mu \mathrm{L})$, miScript universal primer $(2.5 \mu \mathrm{L})$ and miScript primer assay $(2.5 \mu \mathrm{L})$. For normalisation, we used the minimal nuclear U6. The following specific primers were used: mature miR-376c GGUGGAUAUUCCUUCUAUGUU and miR-1268a CGGGCGUGGUGGUGGGGG, as well as mature U6 used as a reference gene (miScript Primer Assay Kit, QIAGEN, USA). A real-time PCR instrument (V.2.0.1, ABI7500) analysed the data. The following cycling conditions were considered: the initial activation process was performed at $95^{\circ} \mathrm{C}$ for $15 \mathrm{~min}$, then a threestep cycling for 40 cycles: denaturation (at $94^{\circ} \mathrm{C}$ for 15 $\mathrm{s})$, then primer annealing (at $55^{\circ} \mathrm{C}$ for $30 \mathrm{~s}$ ) and primer extension (at $70^{\circ} \mathrm{C}$ for $30 \mathrm{~s}$ ).

We normalised the miRNA-376c and miRNA-1268a expression levels to $\mathrm{U} 6$, and the relative expression values were calculated using the $2^{-\Delta \Delta \mathrm{Ct}}$ method. Melting curve analysis was used to validate amplification specificity and the absence of primer dimers in each run.

\section{Statistical analysis}

Data normality was assessed, and continuous data were presented as mean \pm SD or median and IQR for symmetric and non-symmetric distributed data, respectively. We presented qualitative data in frequencies and percentages. $\chi^{2}$ test was used to assess the association between two or more qualitative variables. We used Fisher's exact test if the expected cell count of more than a quarter of cases was less than five. To compare the quantitative variables between two independent groups, Student's t-test and Mann-Whitney $\mathrm{U}$ test were used for parametric and non-parametric data. For non-parametric data, KruskalWallis test was used to compare the quantitative variables between more than two independent groups. Spearman's correlation was used to show the correlation between two continuous non-parametric data. Receiver operating characteristics (ROC) analysis was performed to assess biomarker performance, ${ }^{18}$ with respective maximum accuracy points for both sensitivity and specificity. Positive predictive value (PPV) and negative predictive value (NPV) were also calculated. Significant difference was considered when the $\mathrm{p}$ value was less than 0.05 . All analyses were performed using Statistical Package of Social Science (SPSS) V.22.

\section{RESULTS}

Characteristics of the included population

The study included 100 neonates divided into two independent groups. The case group included 50 full-term neonates with HIE, with a mean gestational age of 37.6 weeks $( \pm 1.1)$, while the control group included 50 matched clinically healthy full-term neonates with no evidence of neonatal HIE, with a mean gestational age of 37.65 weeks $( \pm 0.95)$. Sixty per cent of the case group and $46 \%$ of the control group were male. Participants in the control group had a significantly higher mean weight than neonates with HIE ( $3.14 \mathrm{~kg}$ vs $2.85 \mathrm{~kg}, \mathrm{p}=0.022)$.

With regard to maternal age, we detected no significant difference between the groups $(p=0.248)$. Maternal diseases (including gestational diabetes mellitus, hypertension, pre-eclampsia/eclampsia, oligohydramnios/ polyhydramnios, placenta previa, cardiac disease, hypothyroidism and premature rupture of membranes PROM), as well as complications during delivery, were prevalent in mothers of neonates with HIE $(p<0.001)$. Of the case group, $56 \%$ required mechanical ventilation, while none of the participants in the control group required it $(\mathrm{p}<0.001)$.

Neonates with HIE had significantly lower mean Apgar scores at $1 \mathrm{~min}$ and $5 \mathrm{~min}$ (3.32 vs $9.36, \mathrm{p}<0.001$, and 5.52 vs $9.90, \mathrm{p}<0.001)$. The mean duration of incubation among the case group was 12.7 days $(\mathrm{SD}=10.3$, range $2-47$ days). Thirty-four neonates $(60 \%)$ in the case group and all $(100 \%)$ in the control group survived. With regard to laboratory findings, compared with the healthy controls, neonates with HIE had statistically significant lower levels of haemoglobin and platelet count $(\mathrm{p}=0.026$ and $\mathrm{p}<0.001)$ and higher urea, creatinine, alanine aminotransferase (ALT), aspartate aminotransferase (AST) and CRP levels (all $\mathrm{p}<0.05$; table 1 ). 
Table 1 Demographic, clinical characteristics and laboratory findings of the studied groups $(\mathrm{N}=100)$

\begin{tabular}{|c|c|c|c|c|}
\hline Variables & & Case group $(n=50)$ & Control group $(n=50)$ & $P$ value \\
\hline Gestational age (weeks)§ & Mean \pm SD & $37.6 \pm 1.10$ & $37.65 \pm 0.95$ & 0.149 \\
\hline Weight $(\mathrm{kg}) \S$ & Mean \pm SD & $2.85 \pm 0.48$ & $3.14 \pm 0.34$ & $0.022^{*}$ \\
\hline \multirow[t]{2}{*}{ Gender† } & Male, n (\%) & $30(60)$ & $23(46)$ & 0.161 \\
\hline & Female, n (\%) & $20(40)$ & $27(54)$ & \\
\hline \multirow[t]{2}{*}{ Mode of delivery $\dagger$} & Vaginal, n (\%) & $26(52)$ & $15(30)$ & $0.025^{\star}$ \\
\hline & Caesarean, n (\%) & $24(48)$ & $35(70)$ & \\
\hline Maternal age (years)§ & Mean \pm SD & $31.08 \pm 6.95$ & $32.52 \pm 5.34$ & 0.248 \\
\hline \multirow[t]{2}{*}{ Maternal diseases $†$} & Yes, n (\%) & $18(36)$ & $0(0)$ & $<0.001^{*}$ \\
\hline & No, n (\%) & $32(64)$ & $50(100)$ & \\
\hline \multirow[t]{2}{*}{ Complications during delivery } & Yes, n (\%) & $16(32)$ & $0(0)$ & $<0.001^{*}$ \\
\hline & No, n (\%) & $34(68)$ & $50(100)$ & \\
\hline \multirow[t]{2}{*}{ Mechanical ventilation $\dagger$} & Yes, n (\%) & $28(56)$ & $0(0)$ & $<0.001^{*}$ \\
\hline & No, n (\%) & $22(44)$ & $50(100)$ & \\
\hline Apgar score at $1 \min \S$ & Mean \pm SD & $3.32 \pm 0.55$ & $9.36 \pm 0.631$ & $<0.001^{*}$ \\
\hline Apgar score at 5 min§ & Mean \pm SD & $5.52 \pm 0.60$ & $9.90 \pm 0.631$ & $<0.001^{*}$ \\
\hline \multirow[t]{2}{*}{ Outcome† } & Survived, n (\%) & $34(60)$ & $50(100)$ & $0.001^{*}$ \\
\hline & Did not survive, n (\%) & $16(40)$ & $0(0)$ & \\
\hline Haemoglobin $(\mathrm{g} / \mathrm{L}) \S$ & Mean \pm SD & $129.8 \pm 25.3$ & $142.2 \pm 11,7$ & 0.026 \\
\hline White Cell Count $\neq\left(' \times 10^{9} / \mathrm{L}\right)$ & Median (IQR) & $16(12-77)$ & $13(12-13)$ & 0.065 \\
\hline Platelets $\left(\times 10^{9} / \mathrm{L}\right) \ddagger$ & Median (IQR) & $120(68-228)$ & $285(240-350)$ & $<0.001^{*}$ \\
\hline $\mathrm{pH} \S$ & Mean \pm SD & $7.1 \pm 0.05$ & $7.37 \pm 0.03$ & $<0.001^{*}$ \\
\hline $\mathrm{PCO}_{2} \S$ & Mean \pm SD & $27.3 \pm 4.57$ & $37.4 \pm 3.80$ & $<0.001^{*}$ \\
\hline $\mathrm{PO}_{2} \S$ & Mean $\pm S D$ & $60.5 \pm 7.38$ & $66.2 \pm 2.09$ & $0.008^{*}$ \\
\hline $\mathrm{HCO}_{3} \S(\mathrm{mEq} / \mathrm{L})$ & Mean \pm SD & $12.01 \pm 2.60$ & $21.23 \pm 2.18$ & $<0.001^{*}$ \\
\hline Urea $(\mathrm{mg} / \mathrm{dL}) \ddagger$ & Median (IQR) & $51(34-81)$ & $25(17.5-27.7)$ & $<0.001^{*}$ \\
\hline Creatinine $(\mathrm{mg} / \mathrm{dL}) \ddagger$ & Median (IQR) & $1.7(1.2-1.7)$ & $1.15(0.9-1.30)$ & $<0.001^{*}$ \\
\hline Sodium§(mEq/L) & Mean \pm SD & $132.04 \pm 6.96$ & $138.4 \pm 4.12$ & $<0.001^{*}$ \\
\hline Potassium§(mEq/L) & Mean \pm SD & $4.44 \pm 1.16$ & $4 \pm 1.50$ & 0.09 \\
\hline ALT (U/L) $\ddagger$ & Median (IQR) & $50(35-100)$ & $29(27-30)$ & $<0.001^{*}$ \\
\hline AST (U/L)‡ & Median (IQR) & $40(28-66.5)$ & $21(19.7-24)$ & $<0.001^{*}$ \\
\hline $\mathrm{CRP}(\mathrm{mg} / \mathrm{dL}) \S$ & Mean \pm SD & $6.25 \pm 1.91$ & $4.80 \pm 1.50$ & $0.007^{*}$ \\
\hline
\end{tabular}

${ }^{*} \mathrm{P}<0.05$ is significant.

$\dagger \chi^{2}$ test/Fisher's exact test was used.

$\ddagger$ Mann-Whitney test was used.

$\S$ ¿t-test was used.

ALT, alanine aminotransferase; AST, aspartate aminotransferase; CRP, C reactive protein; $\mathrm{HCO}_{3}$, bicarbonate; $\mathrm{PCO}$, partial pressure of carbon dioxide; $\mathrm{PO}_{2}$, partial pressure of oxygen.

\section{miRNA-376c and miRNA-1268a}

Compared with the control group, neonates with HIE had a significantly lower median level of miRNA-376c $(0.168, \mathrm{IQR}=0.011-0.411$ vs $1, \mathrm{IQR}=0.80-1.20, \mathrm{p}<0.001)$ and a significantly higher median level of miRNA-1268a (13.46, IQR $=2.7-22.8$ vs $1, \quad \mathrm{IQR}=0.4-1.6, \quad \mathrm{p}<0.001)$. Comparing neonates with HIE who survived versus those who did not survive, no statistically significant difference between the groups in terms of miRNA-376c and miRNA$1268 \mathrm{a}(\mathrm{p}=0.124$ and $\mathrm{p}=0.279$ ) was found. There were no significant differences in miRNA-376c and miRNA-1268a among neonates with HIE with regard to clinical staging and MRI findings, as shown in table 2 (all $\mathrm{p}>0.05$ ).
Moreover, assessment of the relationship between miRNA-376c, miRNA-1268a and the demographics of the studied neonates showed no significant differences in terms of sex, mode of delivery, prior maternal diseases and incidence of complications during delivery, except for miRNA-1268a among neonates of mothers with prior diseases $(p=0.037$; table 3$)$. The results of the correlation analysis are shown in table 4 . In terms of miRNA-376c, we detected statistically significant positive correlations with weight, maternal age, Apgar score at $1 \mathrm{~min}$, platelets, $\mathrm{pH}$, partial pressure of carbon dioxide $\left(\mathrm{PCO}_{\mathrm{q}}\right)$, partial pressure of oxygen $\left(\mathrm{PO}_{2}\right)$, bicarbonate $\left(\mathrm{HCO}_{3}\right)$ and calcium, as well as negative correlations with white cell count 
Table 2 miRNA-376c and miRNA-1268a among the studied groups and among neonates with hypoxic-ischaemic encephalopathy as regards Sarnat staging and MRI finding

\begin{tabular}{|c|c|c|c|}
\hline & & miRNA-376c & miRNA-1268a‡ \\
\hline Case groupł & $n=50$ & $0.168(0.011-0.411)$ & $13.46(2.7-22.8)$ \\
\hline \multirow[t]{2}{*}{ Control group $\ddagger$} & $\mathrm{n}=50$ & $1(0.80-1.20)$ & $1(0.4-1.6)$ \\
\hline & $P$ value & $<0.001^{\star}$ & $<0.001^{*}$ \\
\hline Survived $\ddagger$ & $\mathrm{n}=34$ & $0.263(0.011-0.472)$ & $4.56(3.1-24.2)$ \\
\hline \multirow[t]{2}{*}{ Did not survivef } & $\mathrm{n}=16$ & $0.113(0.012-0.223)$ & $13.9(2.6-21.9)$ \\
\hline & $P$ value & 0.124 & 0.279 \\
\hline \multirow[t]{4}{*}{ Clinical Sarnat staging $†$} & Mild cases & $0.259(0.011-0.397)$ & $13.953(0.83-21.75)$ \\
\hline & Moderate cases & $0.095(0.007-0.401)$ & $11.022(2.73-26.7)$ \\
\hline & Severe cases & $0.253(0.016-0.721)$ & $2.644(1.8-20.1)$ \\
\hline & $P$ value & 0.436 & 0.143 \\
\hline \multirow[t]{6}{*}{ MRI findings $†$} & Normal & $0.37(0.012-0.411)$ & $13.9(5.1-23.4)$ \\
\hline & Grade 1a & $0.14(0.007-0.397)$ & $13.7(6.1-21.5)$ \\
\hline & Grade $1 b$ & $0.06(0.007-0.401)$ & $16.7(2.7-26.7)$ \\
\hline & Grade $2 a$ & $0.24(0.106-0.721)$ & $2.6(1.9-20.1)$ \\
\hline & Grade $2 b$ & $0.26(0.50-1.69)$ & $2.6(1.61-280.1)$ \\
\hline & $P$ value & 0.759 & 0.46 \\
\hline
\end{tabular}

Data are presented as median (IQR).

${ }^{*} \mathrm{P}<0.05$ is significant.

†Kruskal-Wallis test was used.

¥Mann-Whitney test was used.

(WCC), urea, creatinine, potassium, ALT and AST (all $\mathrm{p}<0.05$ ). With regard to miRNA-1268a, there were statistically significant negative correlations with gestational age, weight, maternal age, Apgar score at $1 \mathrm{~min}$, platelets, $\mathrm{pH}, \mathrm{PCO}_{2}, \mathrm{PO}_{2}, \mathrm{HCO}_{3}$ and sodium, as well as positive correlations with WBsC, urea, creatinine, CRP, ALT and AST (all p<0.05).

\section{Accuracy of the studied parameters as diagnostic biomarkers} for HIE

The usefulness of miRNA-376c and miRNA-1268a as diagnostic markers, compared with Apgar score and $\mathrm{pH}$, was tested through ROC curve analysis (figure 1). At 0.90 points, miRNA-376c showed a sensitivity and a specificity of $88 \%$ and $68.40 \%$, with an area under the curve of $84 \%$ ( $\mathrm{PPV}=76 \%$ and $\mathrm{NPV}=81 \%$ ). At 2.70 points, miRNA-1268a showed a sensitivity and a specificity of $76 \%$ and $100 \%$, with an area under the curve of $96 \%$ (PPV=77\% and $\mathrm{NPV}=100 \%)$. At less than 6 points, Apgar score showed a sensitivity and a specificity of $100 \%$ (PPV $=100 \%$ and $\mathrm{NPV}=100 \%$ ), while at less than $7.1 \mathrm{pH}$ showed a sensitivity and a specificity of $90 \%$ and $100 \%$ (PPV $=86 \%$ and $\mathrm{NPV}=100 \%$ ). The combined test showed an overall sensitivity and specificity of $89 \%$ and $85 \%$ (PPV=82\% and $\mathrm{NPV}=92 \%$ ).

\section{DISCUSSION}

In the current study, we found that patients with HIE had a significantly lower level of miRNA-376c and a higher level of miRNA-1268a than the control group. We

\begin{tabular}{|c|c|c|c|c|c|}
\hline Variables & & miRNA-376c & $P$ value & miRNA-1268a & $P$ value \\
\hline \multirow[t]{2}{*}{ Gender } & Male & $0.24(0.03-0.439)$ & 0.383 & $8.8(2.2-26.7)$ & 0.526 \\
\hline & Female & $0.66(0.008-0.353)$ & & $15.3(3.3-21.2)$ & \\
\hline \multirow[t]{2}{*}{ Mode of delivery } & Vaginal & $0.24(0.007-0.426)$ & 0.756 & 8.8 (3.3-21.2) & 0.938 \\
\hline & Caesarean & $0.13(0.024-0.426)$ & & $15.4(2.3-23.2)$ & \\
\hline \multirow[t]{2}{*}{ Maternal diseases } & Yes & $0.20(0.021-0.381)$ & 0.733 & $15.3(4.5-25.6)$ & $0.037^{*}$ \\
\hline & No & $0.068(0.006-2.65)$ & & $2.7(1.43-144.1)$ & \\
\hline \multirow{2}{*}{$\begin{array}{l}\text { Complications during } \\
\text { delivery }\end{array}$} & Yes & $0.12(0.007-0.291)$ & 0.067 & 13.9 (4.9-2396) & 0.056 \\
\hline & No & $0.39(0.026-1.81)$ & & $2.6(1.64-22.8)$ & \\
\hline
\end{tabular}

Data are presented as median (IQR).

${ }^{*} \mathrm{P}<0.05$ is significant. 
Table 4 Correlation between miRNA-376c, miRNA-1268a and demographics and clinical data of the studied neonates

\begin{tabular}{|c|c|c|c|c|}
\hline \multirow[b]{2}{*}{ Variables } & \multicolumn{2}{|c|}{ miRNA-376c } & \multicolumn{2}{|c|}{ miRNA-1268a } \\
\hline & Spearman's $r$ & $P$ value & Spearman's $r$ & $P$ value \\
\hline Gestational age (days) & 0.211 & $0.039^{*}$ & -0.319 & $0.001^{*}$ \\
\hline Maternal age (years) & 0.226 & $0.025^{*}$ & -0.298 & $0.003^{*}$ \\
\hline Apgar score at $1 \mathrm{~min}$ & 0.544 & $<0.001^{*}$ & -0.720 & $<0.001^{*}$ \\
\hline Apgar score at $5 \mathrm{~min}$ & -0.054 & 0.711 & $0.712^{*}$ & $<0.001^{*}$ \\
\hline Weight (Kg) & 0.208 & $0.04^{*}$ & -0.249 & 0.013 * \\
\hline Duration of incubation (days) & 0.188 & 0.178 & 0.198 & 0.183 \\
\hline Haemoglobin $(g / L)$ & -0.147 & 0.149 & -0.08 & 0.432 \\
\hline White cell count $\left(\times 10^{9} / \mathrm{L}\right)$ & -0.258 & $0.01^{*}$ & 0.309 & $0.002^{*}$ \\
\hline Platelets $\left(\times 10^{9} / L\right)$ & 0.415 & $<0.001^{*}$ & -0.423 & $<0.001^{*}$ \\
\hline $\mathrm{pH}$ & 0.409 & $<0.001^{*}$ & -0.661 & $<0.001^{*}$ \\
\hline $\mathrm{PCO}_{2}$ & 0.552 & $<0.001^{*}$ & -0.702 & $<0.001^{*}$ \\
\hline $\mathrm{PO}_{2}$ & 0.587 & $<0.001^{*}$ & -0.791 & $<0.001^{*}$ \\
\hline${ }_{8} \mathrm{HCO}_{3}$ & 0.490 & $<0.001^{*}$ & -0.716 & $<0.001^{*}$ \\
\hline Base deficit & 0.201 & 0.176 & -0.156 & 0.151 \\
\hline Urea (mg/dL) & -0.249 & $<0.001^{*}$ & 0.573 & $<0.001^{*}$ \\
\hline Creatinine (mg/dL) & -0.229 & $0.023^{*}$ & 0.526 & $<0.001^{*}$ \\
\hline $\mathrm{CRP}(\mathrm{mg} / \mathrm{dL})$ & -0.09 & 0.39 & 0.412 & $0.019^{*}$ \\
\hline Sodium (mEq/L) & 0.222 & $0.028^{*}$ & -0.497 & $<0.001^{*}$ \\
\hline Potassium (mEq/L) & -0.269 & $0.007^{*}$ & 0.153 & 0.132 \\
\hline Calcium ((mg/dL) & 0.376 & $0.008^{*}$ & -0.034 & 0.740 \\
\hline ALT (U/L) & -0.259 & $0.01^{*}$ & 0.527 & $<0.001^{*}$ \\
\hline AST (U/L) & -0.436 & $0.003^{*}$ & 0.644 & $<0.001^{*}$ \\
\hline
\end{tabular}

${ }^{*} \mathrm{P}<0.05$ is significant.

ALT, alanine aminotransferase; AST, aspartate aminotransferase; CRP, $\mathrm{C}$ reactive protein; $\mathrm{HCO}_{3}$, bicarbonate; $\mathrm{PCO}$, partial pressure of carbon dioxide; $\mathrm{PO}_{2}$, partial pressure of oxygen.

detected no statistically significant difference between neonates with HIE who survived and those who did not survive in terms of miRNA-376c and miRNA-1268a $(\mathrm{p}=0.124$ and $\mathrm{p}=0.279)$. miRNA-376c had high sensitivity but low specificity, while miRNA-1268a had high specificity but low sensitivity, in detecting HIE.

In an experimental animal study, Chen and colleagues ${ }^{19}$ documented the potential role of miRNA-124-3p/Bax
A

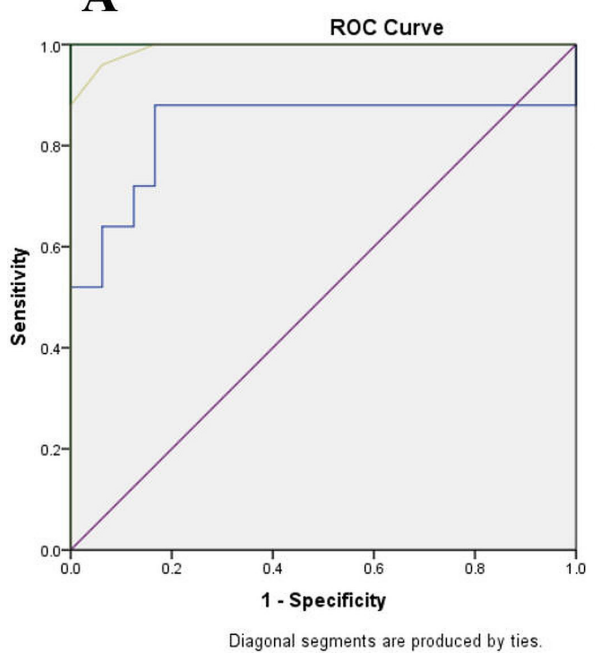

B

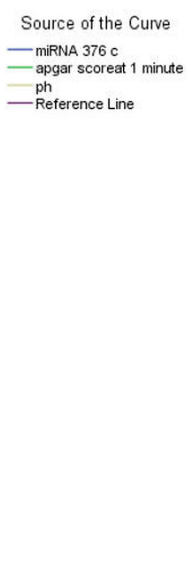

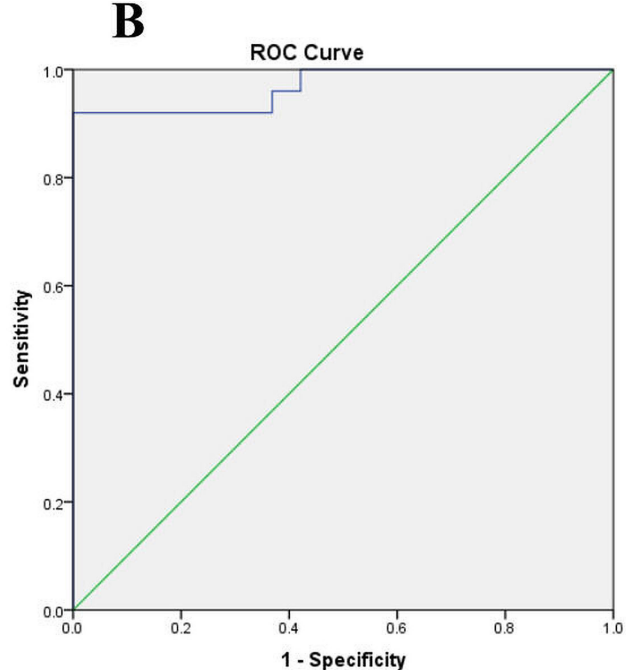

Figure 1 Receiver operating characteristic (ROC) curve of (A) miRNA-376c and Apgar score at 1 min and (B) miRNA-1268a. 
in the pathophysiology of HIE. In a study of miRNAs obtained from dried spots of blood, Ponnusamy et $a t^{20}$ assessed the potential biomarkers for HIE in 30 newborn babies. They studied some selected miRNAs (Let7b, miRNA-21, miRNA-29b, miRNA-124 and miRNA-155) and reported no significant difference among favourable and unfavourable outcome groups for babies with HIE. Other findings that are closely similar to this one used the umbilical cord and/or maternal blood. A previous study by Looney et $a l^{21}$ reported downregulation of miRNA$374 \mathrm{a}$ in the blood obtained from the umbilical cord of infants with HIE. Moreover, Wang $e t a t^{22}$ selectively evaluated miRNA-210 and miRNA-374a in the blood of the umbilical cord of neonates with HIE and suggested its potential role as a biomarker for severity as well as prognosis of HIE.

Our diagnostic analysis revealed that miRNA-376c has an acceptable sensitivity (88\%) but not specificity $(68.4 \%)$ in differentiating neonates with HIE. In our study, patients had a significantly higher level of miRNA1268 a than the control group.

The ROC curve showed that miRNA-1268a was a considerable discriminator to differentiate neonates with HIE, with a sensitivity and a specificity of $76 \%$ and $100 \%$ (cut-off point of $>2.7$ ). In the combined test with both Apgar score and $\mathrm{pH}$, both sensitivities increased to $89 \%$ and the specificity of miRNA-376c increased to $85 \%$.

PPV can predict how likely it is for a person to be diagnosed with a disease in case of a positive test result, while NPV can predict how likely it is for a person to be healthy in case of a negative test result. In our study, the PPV for miRNA-376c was $76 \%$, while it was $77 \%$ for miRNA1268a. The NPV for miRNA-376c was $81 \%$, while it was $100 \%$ for miRNA-1268a.

Temporal expression changes of miRNA-23a-5p, miRNA-27a-5p as well as miRNA-31-5p have been detected in experiments on a piglet HIE model to be considered efficient biomarkers for differentiating hypoxia from infection-sensitised hypoxia. Also, miRNA-374a and miRNA-210 have been shown as crucial regulators in neonatal HIE. Nevertheless, therapeutic hypothermia, the current standard treatment for the management of HIE, has been studied in adult rats experiencing traumatic brain injury, altering miRNA-874 and miRNA-451 expression. These experiments differed in methodology and revealed changes in different miRNAs in neonatal HIE. ${ }^{23}$ Recently, in 2019, O'Sullivan $e t a l^{24}$ studied miRNA to assess both the development and severity of HIE. In their study, the authors documented a decline in miR374a-5p among infants with HIE compared with the controls.

Data from clinical studies of hypothermia for the prevention of brain injury in neonates with HIE suggest that the consensus criteria are likely limiting. ${ }^{25}{ }^{26}$ There are some caveats required for the individual diagnosis of neonatal HIE. Reported data are often incomplete, unreliable and contradictory, especially for blood gases, adequate imaging of the brain, Apgar scores, as well as organ dysfunction testing results. Our study is limited by the low number of included cases, being a single-centre experience. Thus, more extensive clinical trials are warranted to assess this association.

In conclusion, the relative expression of miRNA$376 \mathrm{c}$ and miRNA-1268a was altered in the cord blood of neonates with HIE. In addition, they have moderate diagnostic accuracy in detecting HIE. There is no association between the relative expression of miRNA-376c and miRNA-1268a in terms of MRI and survival findings.

Contributors Conception and design: DARM, WAB. Analysis and interpretation of data: DARM,MAE-ME,SME. Drafting of the paper: DARM, WAB, IT, HMAB, MAE-ME, SME. Manuscript revision for intellectual content: DARM. Final approval of the version: DARM, WAB, IT, HMAB, MAE-ME, SME. All authors agree to be accountable for all aspects of the work. Guarantor: DARM, WAB, MAE-ME, SME, IT, HMAB.

Funding The authors have not declared a specific grant for this research from any funding agency in the public, commercial or not-for-profit sectors.

Competing interests None declared.

Patient consent for publication Consent obtained from parent(s)/guardian(s).

Ethics approval This study involves human participants and the study protocol was approved by the Ethics Committee of Menoufia Faculty of Medicine (IRB 4/2021PEDI2). The study was conducted in accordance with the Helsinki Declaration of 1964, as revised in 2013.

Provenance and peer review Not commissioned; externally peer reviewed.

Data availability statement Data are available upon reasonable request.

Open access This is an open access article distributed in accordance with the Creative Commons Attribution Non Commercial (CC BY-NC 4.0) license, which permits others to distribute, remix, adapt, build upon this work non-commercially, and license their derivative works on different terms, provided the original work is properly cited, appropriate credit is given, any changes made indicated, and the use is non-commercial. See: http://creativecommons.org/licenses/by-nc/4.0/.

\section{ORCID iDs}

Dina Abdel Razek Midan http://orcid.org/0000-0002-4476-8973

Wael A Bahbah http://orcid.org/0000-0001-6145-0572

\section{REFERENCES}

1 Chao CP, Zaleski CG, Patton AC. Neonatal hypoxic-ischemic encephalopathy: multimodality imaging findings. Radiographics 2006;26 Suppl 1:S159-72.

2 Andersen M, Andelius TCK, Pedersen MV, et al. Severity of hypoxic ischemic encephalopathy and heart rate variability in neonates: a systematic review. BMC Pediatr 2019;19:242.

3 Allen KA, Brandon DH. Hypoxic ischemic encephalopathy: pathophysiology and experimental treatments. Newborn Infant Nurs Rev 2011;11:125-33.

4 Douglas-Escobar M, Weiss MD. Biomarkers of hypoxic-ischemic encephalopathy in newborns. Front Neurol 2012;3.

5 Murray DM. Biomarkers in neonatal hypoxic-ischemic encephalopathy-Review of the literature to date and future directions for research. Handb Clin Neurol 2019;162:281-93.

6 Zhang $\mathrm{H}$, Zhou J, Zhang M, et al. Upregulation of miR-376c$3 p$ alleviates oxygen-glucose deprivation-induced cell injury by targeting ING5. Cell Mol Biol Lett 2019;24:67.

7 Wadaa Allah A, Yahya M, Elsaeidy KS, et al. Clinical assessment of miRNA-23b as a prognostic factor for various carcinomas: a systematic review and meta-analysis. Meta Gene 2020;24:100651.

$8 \mathrm{Wu}$ X, Shen J, Xiao Z, et al. An overview of the multifaceted roles of miRNAs in gastric cancer: spotlight on novel biomarkers and therapeutic targets. Biochem Pharmacol 2019;163:425-39.

9 Long X-D, Huang X-Y, Yao J-G, et al. Polymorphisms in the precursor microRNAs and aflatoxin B1-related hepatocellular carcinoma. Mol Carcinog 2016;55:1060-72.

10 Gluckman PD, Wyatt JS, Azzopardi D, et al. Selective head cooling with mild systemic hypothermia after neonatal encephalopathy: multicentre randomised trial. Lancet 2005;365:663-70.

11 Sonoda T, Matsuzaki J, Yamamoto Y, et al. Serum microRNA-based risk prediction for stroke. Stroke 2019;50:1510-8. 
12 Rodil-Garcia P, Arellanes-Licea EDC, Montoya-Contreras A, et al. Analysis of microRNA expression in newborns with differential birth weight using newborn screening cards. Int $\mathrm{J} \mathrm{Mol} \mathrm{Sci}$ 2017;18. doi:10.3390/ijms18122552. [Epub ahead of print: 28 Nov 2017].

13 Morin RD, O'Connor MD, Griffith M, et al. Application of massively parallel sequencing to microRNA profiling and discovery in human embryonic stem cells. Genome Res 2008;18:610-21.

14 Sarnat HB, Sarnat MS. Neonatal encephalopathy following fetal distress. A clinical and electroencephalographic study. Arch Neurol 1976;33:696-705.

15 Shankaran S, Pappas A, McDonald SA, et al. Childhood outcomes after hypothermia for neonatal encephalopathy. N Engl J Med 2012;366:2085-92.

16 Barkovich AJ, Baranski K, Vigneron D, et al. Proton MR spectroscopy for the evaluation of brain injury in asphyxiated, term neonates. AJNR Am J Neuroradiol 1999;20:1399-405.

17 Barkovich AJ, Hajnal BL, Vigneron D, et al. Prediction of neuromotor outcome in perinatal asphyxia: evaluation of Mr scoring systems. AJNR Am J Neuroradiol 1998;19:143-9.

18 Wadaa Allah AM, Abdel Hamid FF, Soliman AF. Evaluation of E2F3 and survivin expression in peripheral blood as potential diagnostic markers of prostate cancer. Turkish J Biochem2020.
19 Chen A, Wang J, Luo F. Role of microRNA-124-3p/Bax axis in neonatal hypoxic-ischaemic encephalopathy. Biotechnol Biotechnol Equip 2020.

20 Ponnusamy V, Kapellou O, Yip E, et al. A study of microRNAs from dried blood spots in newborns after perinatal asphyxia: a simple and feasible biosampling method. Pediatr Res 2016;79:799-805.

21 Looney A-M, Walsh BH, Moloney G, et al. Downregulation of umbilical cord blood levels of miR-374a in neonatal hypoxic ischemic encephalopathy. J Pediatr 2015;167:269-73.

22 Wang Z, Liu Y, Shao M, et al. Combined prediction of miR-210 and miR-374a for severity and prognosis of hypoxic-ischemic encephalopathy. Brain Behav 2018;8:e00835.

23 Cho KHT, Xu B, Blenkiron C, et al. Emerging roles of miRNAs in brain development and perinatal brain injury. Front Physiol 2019;10:227.

24 O'Sullivan MP, Looney AM, Moloney GM, et al. Validation of altered umbilical cord blood microRNA expression in neonatal hypoxicischemic encephalopathy. JAMA Neurol 2019;76:333.

25 Lu Y-L, Yao J-G, Huang X-Y, et al. Prognostic significance of miR-1268a expression and its beneficial effects for post-operative adjuvant transarterial chemoembolization in hepatocellular carcinoma. Sci Rep 2016;6:36104.

26 Greco P, Nencini G, Piva l, et al. Pathophysiology of hypoxicischemic encephalopathy: a review of the past and a view on the future. Acta Neurol Belg 2020;120:277-88. 